\title{
Will It Work? An Initial Examination of the Processes and Outcomes of Converting Course Materials to CD-ROMs
}

\author{
Rob Connoley \\ Deakin University, Geelong, Australia
}

rob.connoley@deakin.edu.au

\begin{abstract}
The Faculty of Business and Law at Deakin University (Victoria, Australia) decided to dispense of all printed post-graduate learning materials and replace them with CD-ROMs from the commencement of the 2006 academic year. In addition, CD-ROMs were developed for a limited number of undergraduate units as part of a future delivery plan for this cohort of students. The following paper describes this project, the reasons underpinning it, and the processes the Faculty adopted to implement the project. The project is ongoing and part of a broader agenda for change that will see an even greater application of electronic technology to teaching and learning within the Faculty. Although only initial findings and observations are possible at this stage, the project provides a basis for longitudinal reporting and, potentially, a guide for other institutions who may be considering such a move. The paper reports on these observations and on those in the educational development arena and suggests that the Faculty will need to learn from these initial experiences and evaluate the project in greater depth to guarantee a smooth transition for all stakeholders.
\end{abstract}

Keywords: Distance education, educational development, online education

\section{Introduction}

In 2005 the Faculty of Business and Law at Deakin University (Victoria, Australia) decided to dispense of all printed post-graduate learning materials and replace them with enhanced CDROMs or other electronic formats. In addition, CD-ROMs were to be developed for a limited number of undergraduate units as part of a similar future plan for this cohort of students. Although this conversion is not revolutionary (see: for example, Savenye, Olina \& Niemczyk 2001; Van der Vyver \& Lane 2004), the initiative signals the future direction to be taken by the Faculty to course development and teaching and learning in general. This paper commences with a description of the project and then explores the reasons underpinning the Faculty's decision to move to electronic delivery of learning materials. This is to be followed by an examination of the proc-

Material published as part of this publication, either on-line or in print, is copyrighted by the Informing Science Institute. Permission to make digital or paper copy of part or all of these works for personal or classroom use is granted without fee provided that the copies are not made or distributed for profit or commercial advantage AND that copies 1) bear this notice in full and 2) give the full citation on the first page. It is permissible to abstract these works so long as credit is given. To copy in all other cases or to republish or to post on a server or to redistribute to lists requires specific permission and payment of a fee. Contact Publisher@InformingScience.org to request redistribution permission. esses that the Faculty employed to implement the project. As this project is relatively new, only preliminary observations can be made at this stage. However, it provides an opportunity to track progress over time and hopefully provide assistance to other institutions considering such a venture. A number of areas, such as student and staff reaction, have been identified that will require 
further analysis and evaluation in the next year. A separate section also identifies the implications for educational development, highlighting the need for a greater integration with other online developments planned in the Faculty and across the university.

\section{Project Description}

The project consisted of three components or sub-projects, all based on delivery by CD-ROM or directly online. The first was the development of a CD-ROM on post-graduate courses offered by the Faculty. It was anticipated that this CD-ROM would primarily have a marketing and information disseminating focus. It was planned to be distributed to all enrolled postgraduate students and to prospective students. Initial discussions determined that the contents of this CD-ROM should include:

- A Faculty-level page - Welcome from the Dean of the Faculty, links to course areas on the CD-ROM, links to university and faculty web pages, search facility across all units (assuming a set of CD-ROMs is provided as part of the second project).

- Course-level pages - A page for each course, with overviews provided by course-team chairs (voice-over PowerPoint slides), employment opportunities, information about professional associations, and links to unit-level pages.

- Unit-level pages - A page for each unit, with an overview/welcome message provided by unit chairs (for example, voice-over PowerPoint slides), how the unit develops graduate attributes, unit-level search facility, and a description of the learning resources.

The second sub-project was the provision of post-graduate unit learning resources on CD-ROM. From semester 1, 2006, all print materials normally supplied to students are to be replaced by a set of CD-ROMs containing all relevant learning materials, including the previously supplied print-only readers. Similar to the third sub-project explained below, only those units offered in semester 1, 2006 were to appear on the first set of CD-ROMs. Thus, 45 Postgraduate units were to be delivered on CD-ROM to approximately 6,500 students in Semester 1, 2006 (and then every semester following). It should be noted at this stage that the Faculty of Business and Law is already delivering a number of units with additional (non-text based) learning resources; some of which are currently provided online and some delivered on unit-specific CD-ROMs. Enrolled students also received a CD-ROM containing the study guides for all post-graduate units offered in a particular semester and had access to study guides and lecture material online. As explained below, the Faculty has been at the forefront in utilising available technology for course delivery and this sub-project illustrates further the Faculty's directions in respect of course development. The basic level of enhancement anticipated to be undertaken was the hyper linking to readings from within study guides. However, additional enhancements, such as audio and video files were also expected to be included.

The third sub-project was the provision of the core units of the undergraduate Bachelor of Commerce onto CD-ROM(s), commencing from semester 1, 2006. The undergraduate program requires the completion of 24 units over three years of equivalent full-time study, of which ten are compulsory or core units. Of these core units one is already offered in a fully on-line mode and another is supplied on CD-ROM along with a printed study guide. Similar to post-graduate students, off-campus students had received print-based study guides and readers, whilst on-campus students had the option of purchasing these materials. In addition, all students have online access to study guides, lecture materials and discussion forums. Although this sub-project was an afterthought, its importance lay in the message it has signalled for the future. The inclusion of these units in this initiative has forewarned students, academics and other key stakeholders of the Faculty's future directions for course material delivery, that is, the eventual replacement all print ma- 
terials. As for the post-graduate units, academics were encouraged to go beyond the hyper linking to readings from within study guides to include audio and video files.

In addition to this project, academics are actively encouraged to progressively enhance their learning materials and place them online for all students.

\section{The Reasons Underpinning the Project}

The project to convert from print-based learning resources to an electronic format can be viewed as a logical extension to developments that have occurred within Deakin University and the Faculty of Business and Law since the early 1990s. Deakin has moved progressively to introduce and expand its online learning resources for more than a decade. For instance, in 1995 Deakin expanded the use of e-mail for academic communication and support services, introduced the FirstClass computer conferencing facilities and expanded its use of the WWW (Calvert 2001, p. 2). In addition, the university has implemented WebCT Vista as its online Learning Management System, known locally as Deakin Studies Online (DSO), since 2003.

The Faculty of Business and Law is one of Australia's most experienced provider of quality distance education programs offering programs by distance education and face-to-face since the 1970s. It is also the largest provider of post-graduate and distance education units in Deakin University. The Faculty has been at the forefront of developments in course delivery, continuing to update delivery methods for this cohort of students, from print-only delivery in the 1970s and 1980s, to print being supplemented by electronic access to study guides on CD-ROMs and via online technologies since the mid-1990s. Currently, the Deakin Business School, in conjunction with other schools within the Faculty of Business and Law, offers postgraduate programs in a wide variety of disciplines including business administration, commerce and international business.

Electronic learning material delivery is a world-wide occurrence and advances in technology have provided educational institutions with greater means to adopt more sophisticated methods of course delivery. These developments have been particularly beneficial for Deakin University, which has approximately 40 per cent of students studying in an off-campus mode. Similar to other higher education institutions, online technologies at Deakin are aimed at enriching learning experience, adding flexibility and complementing traditional teaching methods. Deakin has also pursued this path to better prepare students in using online technologies, particularly when they enter the workforce. This direction has been supported by a number of key decisions. In 2004 all Deakin units were required to have at least a basic online environment (see table 1) for information, resources and communication, with some units increasing their online presence to include more interactive learning resources (levels 2 and 3). The university also decided that all commencing undergraduate students from 2004 are expected to successfully complete at least one unit of study in a fully online mode at some point in their program of study.

The university has also imposed targets on faculties to increase the number of units they offer at an extended online mode (or level 2). This follows feedback that the level 1 online requirement did not represent a major transformation of teaching and learning at Deakin. For instance, prior to 2004, the university already had 68 percent of units meeting a level 1 requirement. Faculty management realised that only a small number of under-graduate and post-graduate units had an online presence at levels 2 and 3. The production of print-based readers meant most units were non-compliant with these levels. Thus, the conversion to CD-ROM was a means of meeting the new online targets.

A move to an electronic format required a shorter lead time to produce, resulting in fewer delays in getting material to off-campus students. It also was cheaper for the faculty to produce. Like other higher education institutions in Australia, Deakin, and consequently its faculties, is facing a 
constantly tighter financial environment, commonly requiring action to reduce costs. In the past the Faculty provided students with both a CD-ROM and a hard copy of study guides and readings at no additional charge. The hard copies were provided in high-quality binders and cost the faculty around \$250,000 each year. In contrast, the cost of providing each student with material on CDROM would cost around \$20,000 per semester. A CD-ROM was also seen to more easily exploit resources from a wide range of sources and in many formats compared to print-based materials.

The decision to favour CD-ROMS, relative to DSO, was due to the difficulties of online access in the more remote areas. This was an important consideration for the Faculty as many students enrolled in post-graduate units reside in regional and remote locations. The placement of all learning resources onto CD-ROM format could free students from downloading large files, such as audio and video files, some of which were prohibitive from being efficiently sourced from DSO. Though online technology has become increasingly sophisticated, download times continue to limit effective delivery, particularly in geographical areas serviced by Deakin University. (See Table 1.)

\begin{tabular}{|c|c|}
\hline & Table 1: Deakin Categories of Online Activity \\
\hline Category & Features \\
\hline $\begin{array}{l}\text { Level 1: } \\
\text { Basic Online }\end{array}$ & $\begin{array}{l}\text { A Deakin Studies online (DSO) site established. } \\
\text { The DSO site will include, where appropriate and feasible and where they exist, the unit } \\
\text { guide, a 'resources area' where an electronic version of the readings (where appropriate) } \\
\text { and other resources might be placed, and the opportunity for the teaching staff to com- } \\
\text { municate with students through a noticeboard (one-many communication e.g. an- } \\
\text { nouncements). A facility for structured online interaction between teacher and students } \\
\text { will also be available to use at the choice of the lecturers involved in the unit, with the } \\
\text { proviso that all students in unites that do not meet face-to-face at least once a week will } \\
\text { have such opportunities for facilitated online interaction. The unit chair must be pre- } \\
\text { pared to report to their unit community through the DSO site established for their unit. } \\
\text { This may include complementary use of email in the first instance. Student expectations } \\
\text { about communication should be managed (i.e. they are told how they should communi- } \\
\text { cate with teaching staff, and how soon they should expect a reply). }\end{array}$ \\
\hline $\begin{array}{l}\text { Level 2: } \\
\text { Extended } \\
\text { Online Unit }\end{array}$ & $\begin{array}{l}\text { In addition to the above: } \\
\text { The study guide for that unit } \\
\text { Additional DSO options included in the unit and available for students } \\
\text { Additional resources available to students (e.g. additional electronic content, CD ROMs } \\
\text { with additional material, video and audio streaming, etc.) } \\
\text { Additional and/or compulsory use of advanced communication and instruction facilities } \\
\text { More advanced and diverse pedagogies imbedded. }\end{array}$ \\
\hline
\end{tabular}




\begin{tabular}{|c|c|}
\hline $\begin{array}{l}\text { Level 3: } \\
\text { Wholly } \\
\text { Online Unit }\end{array}$ & $\begin{array}{l}\text { All content (either commercial print-based textbooks or commercial e-texts may be used } \\
\text { as supplementary material) } \\
\text { All communication and interaction with students } \\
\text { Assignment submission and feedback (examinations will move online when the Univer- } \\
\text { sity is administratively ready) } \\
\text { Each unit will have at least ONE session of interactive communication (synchronous, } \\
\text { asynchronous, or both) between teacher and students online at least weekly or as estab- } \\
\text { lished at the beginning of the course. Such interactive sessions will have an assessable } \\
\text { component where appropriate. To ensure access for all students until bandwidth issues in } \\
\text { Australia are addressed, additional resources such as video and audio will be provided } \\
\text { on CD-ROMs for off-campus students where appropriate. (This will be reviewed annu- } \\
\text { ally.) }\end{array}$ \\
\hline
\end{tabular}

The move was not devoid of risk and the Faculty took these into consideration in their deliberations. The major risk is the reaction by students (see: for example, Van der Vyver \& Lane 2004). At the stage of the project, it is still an unknown variable. Informal discussions with academics noted some apprehension by students and the risk of student discontent was potentially high. Faculty management also perceived the provision of readings in addition to study guide material as a significant and immediate enhancement. In addition, the course level CD-ROM (the first subproject) was also an added advantage. In anticipation of potential student dissatisfaction, the Faculty provided an option for students to purchase a hard copy of study guides and readers where applicable at cost. In addition, the third sub-project was a deliberate move by the Faculty of Business and Law to prepare all stakeholders of the future direction of the university.

A further risk was in the responses from academics. This is a very real concern, as academics had already shown some reluctance to enhance materials beyond the level 1 requirement on DSO. Faculty management were aware that the short time frame meant it would be impossible to enhance all unit resources on the first set of CD-ROMs. Resource constraints also meant that the scope of value adding to existing learning resources would most likely be limited in the first run, even with strong encouragement from the Dean and Associate Dean. Academics were subsequently encouraged to continue to develop learning enhancements and place them directly onto DSO.

\section{The Process}

Faculty teaching and learning representatives and representatives from the university's Knowledge Media Division (KMD) initially met in February 2005 to discuss the possibility of converting learning materials to CD-ROM. However, it was not until April 2005 that the Faculty formally presented its project to the University's Teaching and Learning Committee. From that time onwards, a number of measures were taken to see this project to fruition.

The decision to move to CD-ROM required a change to the traditional course development processes. The first area to be changed was the Faculty's learning materials planning cycle. Prior to this project, the Faculty had a three- year cyclical process for learning material updates. The planning cycle was constructed on advice from unit teams or from the unit chair as to the extent to which learning materials were to be updated, generally ranging from either no revision, a minor revision or a major re-write. Unit Chairs (academics responsible for coordinating the curriculum, teaching and assessment in a unit) coordinate the development of learning resources for the unit. There are many models for the way units are presented and developed. Under this cyclical approach, the Unit Chair is to keep the Faculty Production Manager informed of plans for unit development so that the necessary Faculty and university resources could be assigned. For minor 
updates, the Faculty Production Manager publishes a schedule stating when different units should complete the work ready for the next offering of the unit. If a unit is undergoing a minor update, the Unit Chair must ensure that a study guide and other learning resources are downloaded (from the Faculty web site), updated and uploaded (again via the Faculty web site) by the due date. For cases where there is a major redevelopment of learning resources, the Unit Chair must coordinate these. The Faculty Production Manager also provides academics with templates in a Word format on study and unit guide preparation and production.

A previous entitlement to a number of units (approximately 10) that would receive 'above-theline' or high level KMD support continued, as this generally meant constructing units for the fully online (or level 3) mode. The role of KMD is to provide a range of support services to assist faculties in developing learning materials through such services as audio production (plan, record, edit, format and post produce most types of audio content for delivery via CD-ROM, Audio CD, DVD and online systems), CD-ROM production, copyright advice, desktop publishing, graphic design, lecture streaming, and multimedia and website development. This Division also undertakes quality checks on course materials such as checking whether materials meet accessibility requirements. KMD has also recently provided access to showcase exemplars on electronic learning from staff across the university.

The Faculty and KMD personnel realised that the production of multimedia learning objects was not necessarily a straightforward process, requiring a range of skills and personnel including academics (subject experts), multimedia producers, educational developers, and production staff working together in order to meet the Faculty expectations (see also Brett \& Nash 1999, p.19). Regular meetings were consequently conducted between representatives from the Faculty's Teaching and Learning unit and personnel from KMD throughout 2005. These meetings covered issues such as design features, level of support necessary, technical and system requirements, timelines, quality checks and procedures for enhancing learning materials. Key responsibilities were also allocated at these meetings. KMD was responsible for the technical specifications and the Faculty responsible for managing the conversion of learning materials. KMD was also ultimately responsible for ensuring the materials were burned to CD-ROMs.

Faculty management were cognisant of the need to gain examples of enhancements from staff, particularly given the short time frame for development and the challenge to the traditional development cycle where resources are allocated for such pursuits. To assist, the Faculty decided to give more discretion to academics and unit teams to convert learning resources to CD-ROM. This bottom-up approach had a significant potential advantage of creating a greater number of enhancements relative to the limited number that could be provided with KMD support.

Initial meetings were held between the Dean, the Associate Dean - Teaching \& Learning and the Heads of Schools (HoS). These meetings were aimed at providing the HoS with details about the process for enhancement and their expected contributions to the first CD-ROM. They were also strongly encouraged to ensure unit teams within their Schools commenced enhancing materials as soon as possible. Meetings with affected staff across all campuses followed these initial meetings with the HoS. Although face-to-face meetings were preferable, minimal turnout meant most information was subsequently distributed to staff via email and telephone. Staff were advised that they would be doing students a disservice by forcing them to read long pages of text on a computer screen and so should be examining ways to reduce content in favour of other learning objects, such as digital photos, audio files, video files, streamed lectures, interactive demonstrations, and text-based readings.

Educational development support was also available to academics. The Faculty currently has two dedicated educational development staff in addition to the Associate Dean to assist academics. Although it was not feasible for these persons to work with all unit teams, they were able to assist 
with some and also provide assistance through the development and distribution of examples being used in other unit teams. Educational developers were also able to start to provide unit teams with access to instructions and guidelines for creating learning objects.

The Faculty also took a more unique step of creating a shared site for learning resources development. The shared site provided individual folders for all units and these contained all the current learning resources (except those specifically designated for DSO). This shared site was designed to allow unit teams to manage the redevelopment of their learning resources of CD-ROM contents whilst in development. As noted above, there was a concerted effort on behalf of the Faculty to ensure ownership for development rested with unit teams. This site was established to enable continuous development and access to examples from other units.

Once updated, academic unit teams could revisit the updated resources prior to signing-off for final production by KMD. Unit teams were also advised that after they had reviewed and signed off on the unit's materials, a copy of the resources in editable form was to be placed into a new site folder in the shared drive. This enabled academics to continue to develop their learning resources in readiness for the next offering of the unit or onto DSO.

\section{The Outcomes to Date}

A full and extensive analysis of the project has not been possible at the time of writing as the unit material is now being returned to academics for a final examination prior to be burned on to CDROMs. In addition, no feedback from students has been possible. However, some initial thoughts can be presented in readiness for a more in-depth analysis during the next few months. The findings are important to identify at this initial stage since the project has mapped out the future path for all learning materials development within the Faculty. The first set of findings report on outcomes of the three sub-projects and the processes employed by the Faculty. This will be followed by an identification of the implications for educational development practices within the Faculty.

\section{Project Outcomes}

Project outcomes are presented for the three sub-projects.

\section{Sub-project 1: Development of a CD-ROM on post-graduate courses offered by the Faculty}

This sub-project was relatively straight forward from a Faculty's perspective, compared to the other two sub-projects. Apart from the audio presentations from the Dean and from course directors, many other resources such as, program details, course structures and study assistance, were already available for burning onto CD-ROM. Throughout the development of this sub-project, progressive details were placed online for Faculty staff to view and provide feedback to KMD via the Faculty's Associate Dean Teaching and Learning. This CD-ROM contained much of what was planned. A home page was developed which included a welcome message from the Dean (along with a printable online transcript). A copy of the home page of sub-project 1 CD-ROM is provided in Figure 1.

From the home page links were provided to a range of other pages/locations including postgraduate programs, methods of applying, money matters, study assistance, and instructions for how to use the CD-ROM. All the post-graduate programs can be examined from the links on the programs home page. Students will be able to access each program via the hyperlinks on the home page. Each program page provides at least a text-based course overview and course structure. Some program pages have also added audio recordings and transcripts explaining additional features including employment opportunities and the relevant professional associations (see Figure 2). 


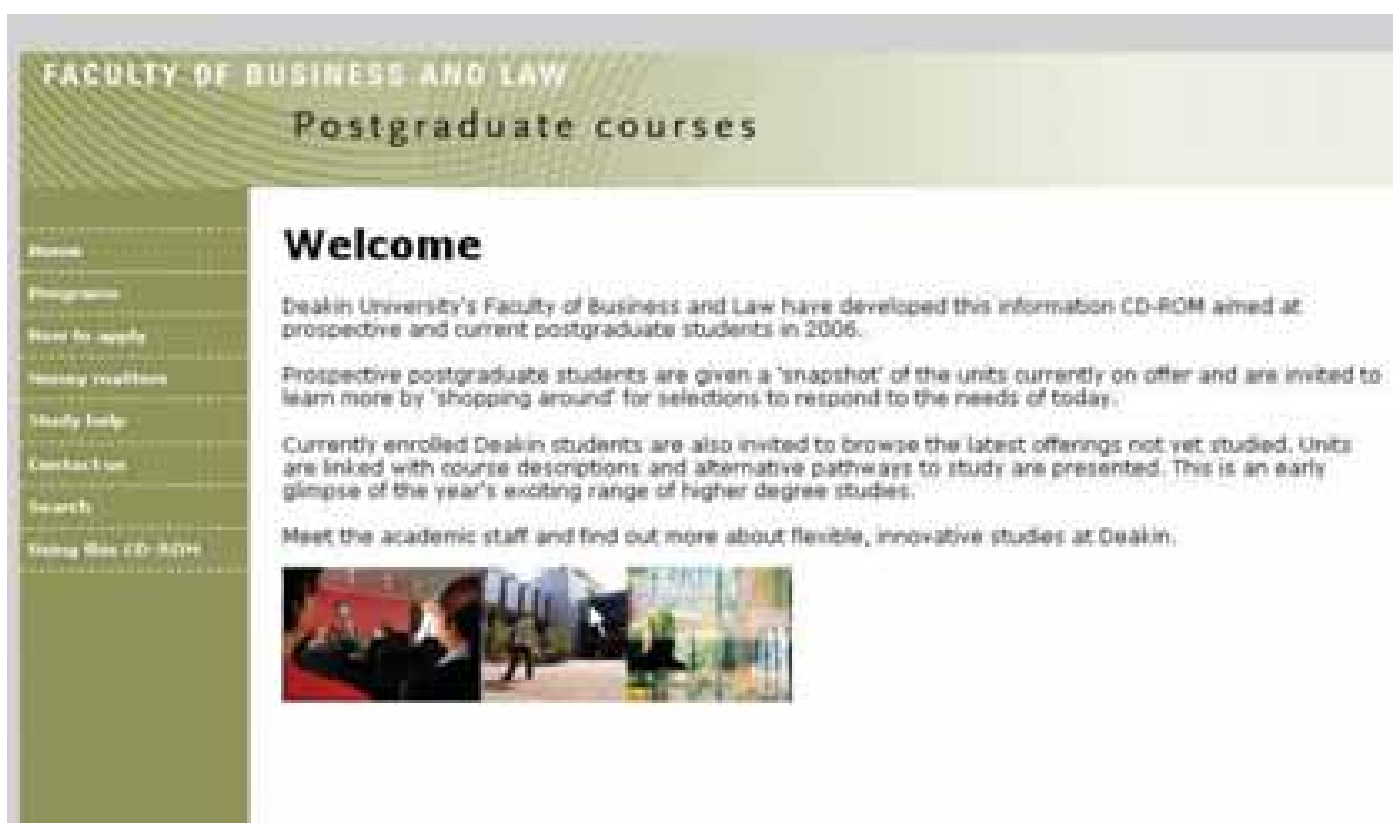

Figure 1: Sub-Project 1 - Home Page CD-Rom

\section{Accounting}

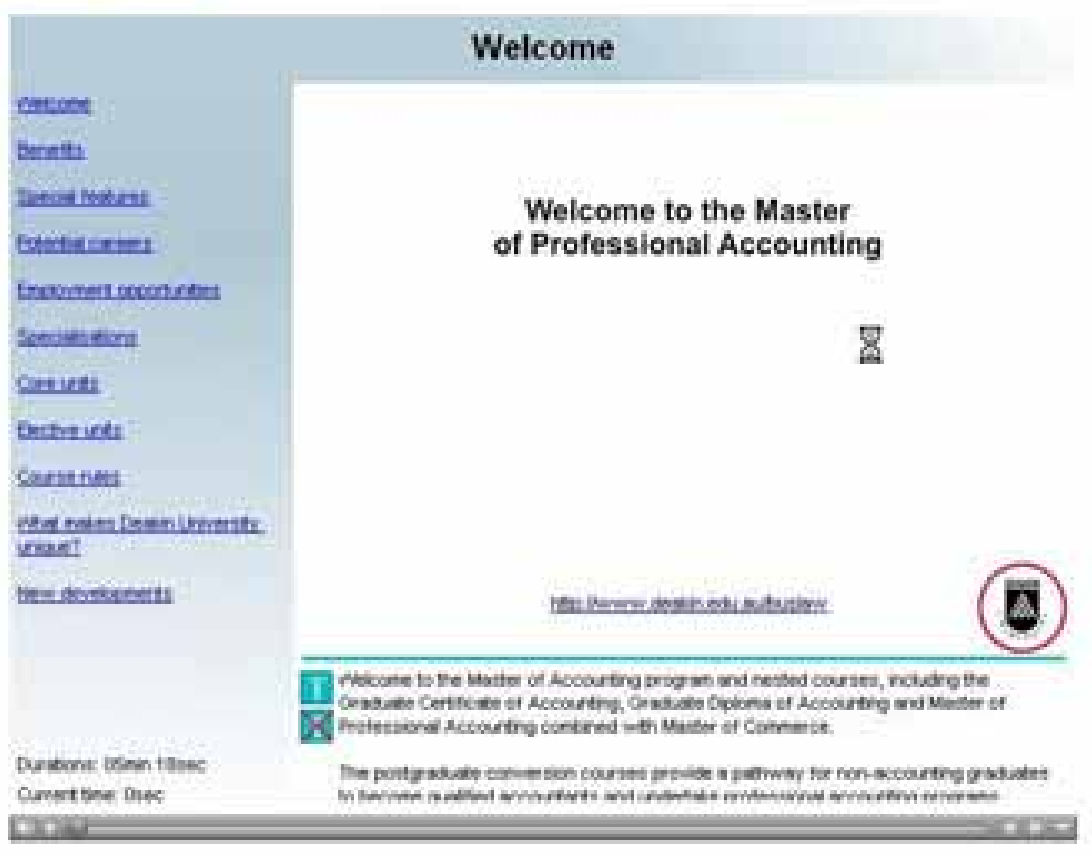

Figure 2: Sub-Project 1 - Program Page 


\section{Sub-project 2: Conversion of post-graduate learning materials to CD- ROMs}

This sub-project was by far the most challenging for the Faculty. As noted above, the Faculty had been gradually increasing its adoption of electronic formats in the delivery of learning materials for many years. However, the number of units voluntarily moving to an electronic format only was quite slow. This sub-project sought to complete this push and signal a future push for electronic feedback. So what has been the result at this point in time? The level of enhancement in this, the first run, can be described as variable, with most semester 1, 2006 units (75 per cent) enhanced to the Faculty's basic level, where readings have been hyperlinked to a text-based study guide. This was not an unanticipated outcome, given the cultural change required, the tight timelines set to complete the conversion, and the limited funds to devote to developing learning enhancements. It is also reflective of the traditional text-heavy approach taken by academics to post-graduate learning materials development. This is an issue raised later in the paper in terms of implications for educational development. In response, the Faculty has strongly encouraged unit teams to continue to work on developing additional learning objects for either placement on their DSO site in readiness for semester 1, 2006.

The majority of units had a basic home page interface, listing topics and hyperlinking to pdfversion study guides (Figure 3). From the study guide, further links were added to pdf-version readings.

\section{International Labour Law}

Unit home Credits Learning support About this CD-ROM Web links Search:

\section{Topics}

The following links open Adobe Acrobat (PDF) files. If you do not have Adobe Reader installed on this computer, please go to the 'About this CD-ROM' page for instructions.

- Topic 1 - Introduction to international labour law

- Topic 2 - Theoretical foundations for international labour requlation

- Topic 3 - The International Labour Orqanization (ILO)

- Topic 4 - ILO fundamental conventions

- Topic 5 - Labour issues arising from the multinational enterprise (MNE)

- Topic 6 - Overview of supra-national labour requlation

- Topic 7 -Labour requlation in the European Union

- Topic 8 - The NAFTA (North American Free Trade Agreement) labour side agreement

- Topic 9 -Introduction to comparative labour law

- Topic 10 -Australian labour law

- Topic 11 - United States labour law

- Topic 12 - Asian labour law-Tiqers and developing countries

- Topic 13 - Chinese labour law and transplantability

Figure 3: Sub-Project 2 - Common Home Page 
The units that enhanced learning resources beyond this basic level were either converted to HTML (Figure 4) or redesigned using PowerPoint or Roadmap Tools, the latter tools being developed in-house by the Associate Dean of Teaching and Learning (Figure 5). The units prepared on these bases generally restructured the previously heavy text-based study guides and added additional features such as video and audio clips. Lecture slides were used to replace study guides in most of the units that used the Roadmap Tools.

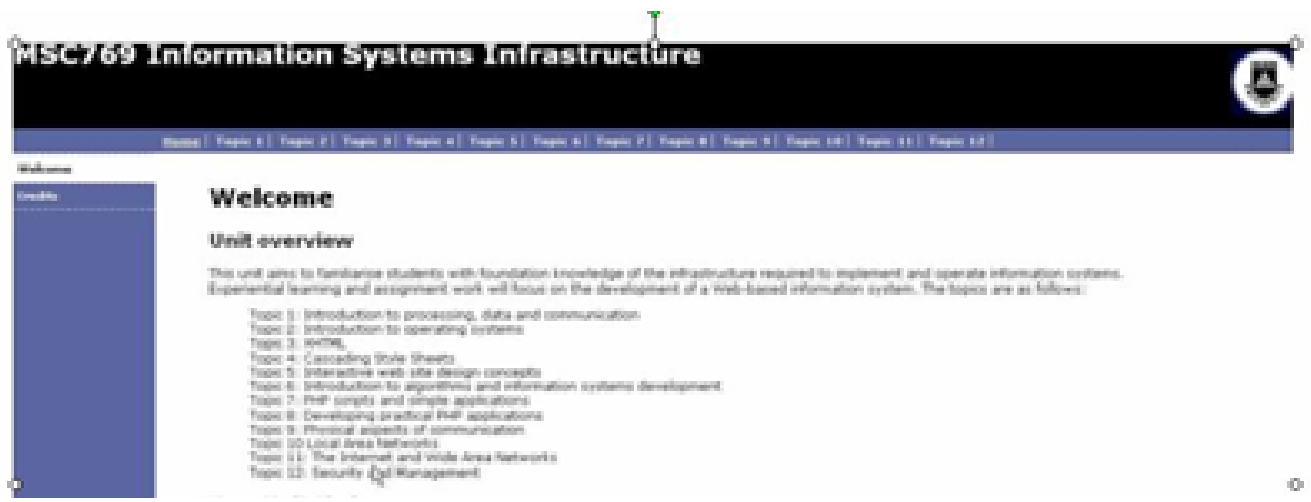

Figure 4: HTML Structure

\section{MPC701 Information Systems For Business Learning Resources Roadmap}

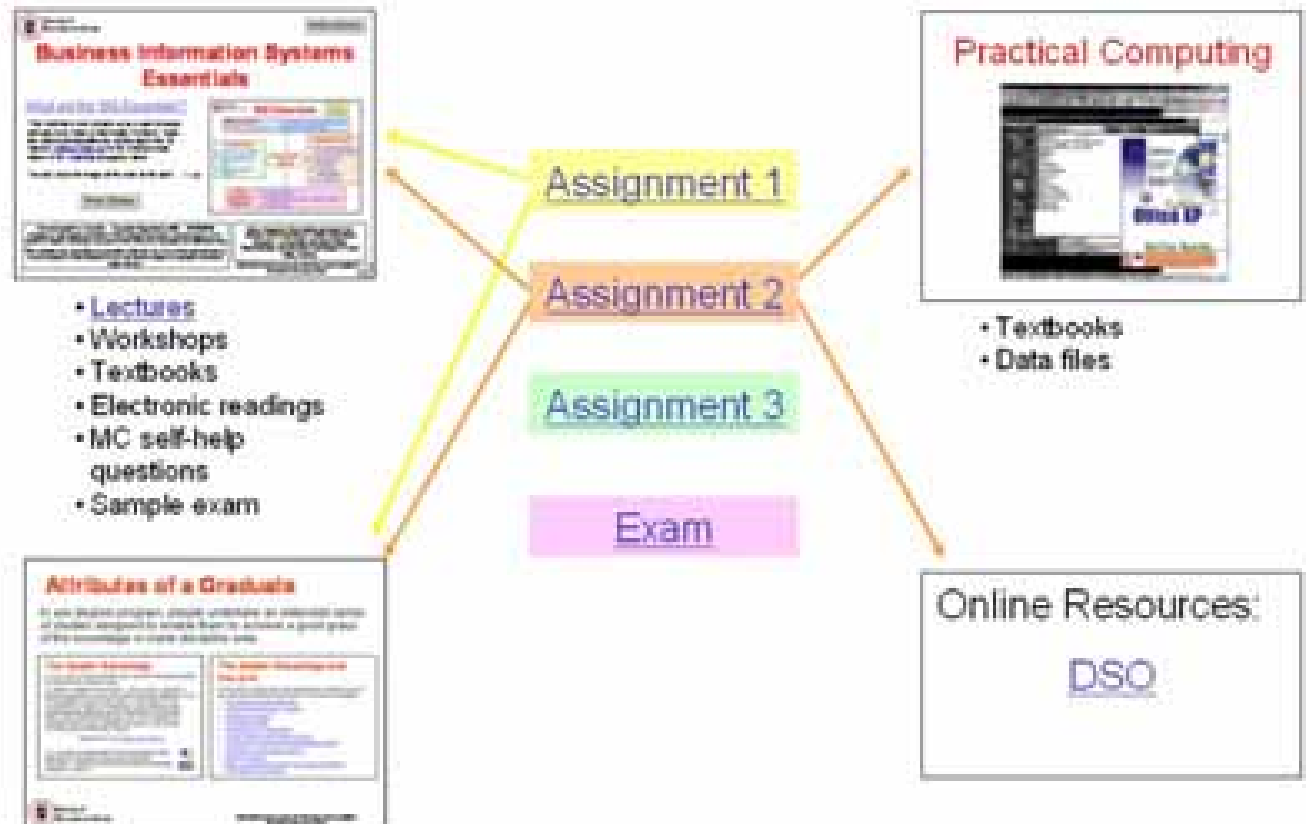

Figure 5: Structure Using Roadmap Tools (PowerPoint) 
Interview math Sareen Fereirs, GS:

iers the toromat
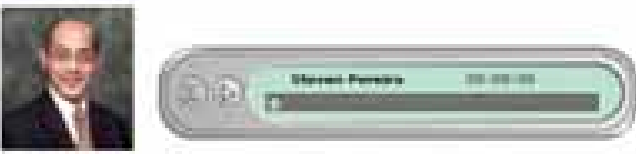

4 wateo

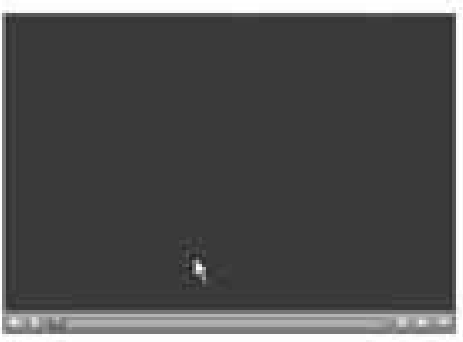

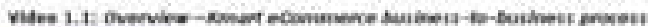

viem the trassereat

? netarison

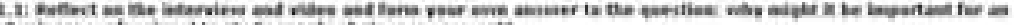

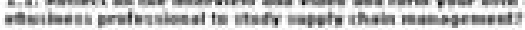

Figure 6: Sub-Project 2 - Example of Enhancements From HTML

\section{Computer Organisation (The Hardware)}

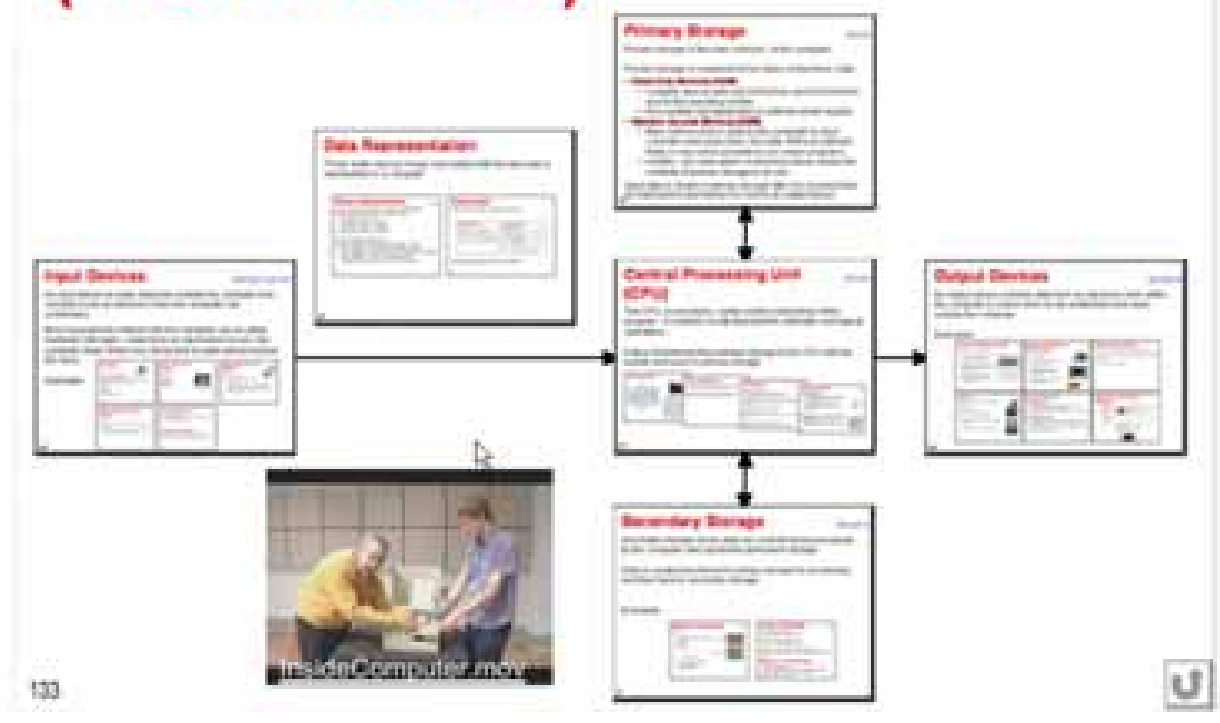

Figure 7: Sub-Project 2 - Example of Enhancement using Roadmap Tools 
The enhancements ranged from a complete overhaul of study materials to the addition of videos and audio learning objects. Examples of the inclusion of enhancements are presented in Figures 6 and 7 . The learning objects were able to be viewed from links within the redesigned learning materials.

\section{Sub-project 3: Provision of the core units of the undergraduate Bachelor of Commerce onto CD-ROM(s)}

Although the core units of the Bachelor of Commerce degree attracted less attention from Faculty management than the post graduate level units, the conversion represents the start of a future plan for course materials. This future is one where all undergraduate print-based learning materials will be replaced by electronic formats.

As noted earlier, one core unit is already offered entirely online and one was delivered on CDROM (along with a printed study guide). During the conversion process this unit opted to replace the print study guide with an updated version and be placed onto the CD-ROM. Of the eight remaining units, only three were unable to be enhanced, primarily due to staffing changes. Five units underwent more extensive changes, with four adopting a concept mapping approach using the Roadmap Tools (see Figure 5) and one received KMD support to convert their existing learning materials to a HTML format (see Figure 4). Similar to the post-graduate units, these undergraduate units also provided features such as audio and video clips, lecture streaming, and a range of publisher learning objects (such as online topic multiple choice tests). In is anticipated the remaining core units will undergo extensive modifications before the end of 2006.

\section{Process outcomes}

Some initial observations can also be presented about the processes used by the Faculty to implement these sub-projects. This is an important area for evaluation as the process will commence again in January/February 2006 for semester 2 offerings. The change was far more complicated than originally anticipated by Faculty management, and many more unit teams than had been anticipated were not enhancing their materials beyond a basic level. It appears that the level of enhancement was primarily dependent upon the level of support directly provided to individual units by KMD or by the Faculty's teaching and learning staff and to a limited extent on the pressures applied by the HoS. The limited enhancement by the majority of units is also indicative of the major cultural change to course development that this project entailed. Although meetings were held with academic teams, the benefits of conversion were not self-evident in informal discussions with individual academics.

Short comings were also evident in the areas of project management and in the level of resources required to effectively enhance learning. An overall project plan would have mapped out key tasks, responsibilities and issues to address prior to the project's implementation. It would have also anticipated constraints in the conversion process and in the level of resources required. However, limited time and resources resulted in the project management tasks generally being done 'on the fly'.

The level of resources dedicated to the project also needs to be planned. Multimedia enhancements are time consuming, sometimes involving many programming hours and material writing by academics. The Faculty cannot dedicate educational development resources to each individual unit meaning that in future the necessary tools need to be made more readily accessible by unit teams. The establishment of the shared development site has provided an avenue for an efficient distribution of required technology. Although the establishment of a shared site for unit development did not result in a major redevelopment at the local level or in the sharing of learning objects, it still appears to offer considerable advantages for future educational development. A key 
factor in its success will be determined by the extent to which the Faculty is able to convince academics of the ways in which electronic learning materials can enhance student learning and be able to provide the necessary technological tools and training in their application.

\section{Implications for Educational Development}

Both the time span and the extensive number of units offered by the Faculty of Business and Law limited the level of direct educational development support available to individual unit teams. Also the establishment of the shared development site has meant that academics can progressively develop resources for their unit and these not be analysed as to appropriate fit within their learning resources. Since the Faculty is pursuing the conversion of units at the undergraduate level, opportunities for educational developers to work individually with all unit teams will be even more unlikely in the future. This will necessitate developers to use other means of skilling up academics in their conversion of learning materials to an electronic format. In addition, as academics are also required to complete other tasks related to learning, such as preparing course and unit outlines and unit guides, some means of integration of these to this project is also pressing.

A first task will be for educational developers to increase the level of academic understanding of appropriate instructional design principles for electronic learning materials. Observations to date have indicated that academics require a foundation of knowledge of instructional principles and be provided with examples that could be adapted or applied to suit their units. In addition, standards for accessibility and other matters will also need to be communicated to academics. People's first instinct is to use it to do what they already do and consequently it is important for educational developers to work on assisting changing this mind set. The current mind set is one of producing substantial bodies of print-based resources. The move to electronic delivery will place pressure on this mind set. The anticipated introduction of additional electronic learning requirements, such as the introduction of electronic feedback during 2006, will also challenge existing practices of assessment and feedback currently used by academics.

Developers will also need to keep abreast of advances made available by new technologies and assist in spreading these to academics. Technology provides opportunities for the development of innovative and powerful interactive educational material (Aldrich, Rogers, \& Scaife, 1998, p.321). These technologies provide new ways of delivering content, and they often promote learner-centred environments that can motivate students and add variety to learning. In this environment, instructional units are often accompanied by a liberal use of multimedia that is intended to add excitement to the lesson and hold the learner's attention. However, visual and auditory components that are intended to stimulate do not always make for sound instructional design in multimedia delivery and can quickly become counter-productive to learning (Sorden, 2005, p.264). A central problem is that the CD-ROMs could be simply a mishmash of images sounds and video offering little more than light entertainment (Aldrich et al., 1998, p.321). Time did not permit an analysis of the educational value of the enhancements provided by unit teams. Post graduate materials have also been very text-heavy and a major implication for educational developers to encourage unit teams to put the interactivity provided by the new technology to good use. Academics need an understanding of a range of media/technologies, their sources and possible educational uses, including the benefits of integrative approaches. This may involve developers assisting in the preparation of online tutorials for unit teams in how to apply particular tools to their learning materials. Through the consideration of a range of cases, participants should develop and/or review the current media/technologies mix in their teaching area with a view to suggesting enhancements associated with the use of digital media, via the mapping of learning resources, and new styles of student learning guides. The creation of a shared development site provides an ideal location for educational developers to direct academics to relevant exemplars. 
Throughout 2006, it is planned to develop resources to instruct academics on capturing demonstrations on computer screen, including audio voice-overs and for tools to create and edit web pages.

Educational developers will also need to maintain an awareness of current and future trends in electronic delivery, particularly in identifying good practices from institutions following this path and particularly those which are providing electronic assessment and feedback. This will add value to decision makers about the development and delivery of courses in the future, particularly as the Faculty seeks to extend the application of electronic means of learning.

\section{Conclusion}

Higher education institutions are likely to continue to face pressure to deliver high-quality education to many learners at a reasonable cost (Savenye, Olina, \& Niemczyk, 2001, p.381). Advances in technology have made the production of CD-ROMs an efficient and potentially effective educational strategy to meet this need. The Faculty of Business and Law at Deakin University decided to move to CD-ROM format in late April 2005 for its study materials, replacing the weighty paper-based format familiar to most students. It also decided to initiate undergraduate students to a CD-ROM delivery format in the core units of their Bachelor of Commerce degree.

At this stage, the Faculty has placed considerable faith that students and academics will accept this initiative and has also indicated there will be 'no going back'! Given previous studies of similar conversions (Van der Vyver \& Lane, 2004), feedback from students and academics is essential. In respect of students we need data on learning styles and whether the learning materials cater for different styles. A project to evaluate the learning styles of law students is planned for 2006 and this will assist in informing the Faculty on approaches to use in the post-graduate level. An inquiry is warranted into how academics can learn about the educational value of technological enhancements, whether their developments are being shared with colleagues, and importantly the extent to which educational principles are informing the development of these enhancements. In addition, learning from the practices of other institutions pursuing similar forms of learning is essential, particularly assessment practices and the provision of feedback to students. An analysis of these areas will ensure the Faculty of Business and Law can gain the maximum advantages from this delivery format. It will also hopefully provide other interested parties with advice of how to guide, encourage and organise teachers to develop educationally valuable learning materials and methods with new technology.

\section{References}

Aldrich, F., Rogers, Y. \& Scaife, M. (1998). 'Getting to grips with "interactivity”: helping teachers assess the educational value of CD-ROMs', British Journal of Educational Technology, Vol. 29, No. 4, pp. 321-332

Brett, P. A. \& Nash, M. 1999. 'Multimedia language learning courseware: a design solution to the production of a series of CD-ROMS', Computers \& Education, Vol. 32, pp.19-33

Calvert, J. 2001. 'Deakin University: Going Online At A Dual Mode University', International Review of Research in Open and Distance Learning, Vol. 1, No. 2, pp.1-20

Savenye, W. C., Olina, Z. \& Niemczyk, M. 2001. 'So you are going to be an online writing instructor: issues in designing, developing, and delivering an online course', Computers and Composition, Vol. 18, pp. 371-385

Sorden, S. D. (2005). A cognitive approach to instructional design for multimedia learning, Informing Science Journal, 8, 263-279. Available at http://inform.nu/Articles/Vol8/v8p263-279Sorden34.pdf 
Van der Vyver, G. \& Lane, M. S. (2004). Higher education course content: Paper-based, online or hybrid course delivery? Paper presented at the Informing Science \& Information Technology Education Joint Conference, Rockhampton, Queensland, Australia, June 25 - 28. Retrieved 24 November 2005 from http://proceedings.informingscience.org/InSITE2004/109vande.pdf

\section{Biography}

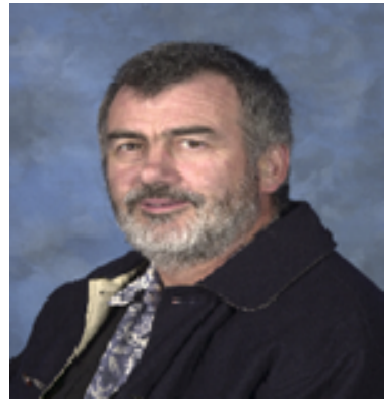

Rob Connoley has been employed in the Faculty of Business and Law as a Lecturer in Teaching and Learning/Educational Developer since 2004, for the provision of educational development in the areas of assessment, flexible teaching and learning, and online learning resources development and delivery. Previous to 2004, Rob has worked as an instructional designer, held various management positions in government/semi-government organisations and has taught in universities and secondary schools. Rob is currently completing his $\mathrm{PhD}$. 